Review

\title{
Internet Access by People with Intellectual Disabilities: Inequalities and Opportunities
}

\section{Darren Chadwick *, Caroline Wesson and Chris Fullwood}

Psychology Department, School of Health and Wellbeing, University of Wolverhampton, Wolverhampton WV1 1LY, UK; E-Mails: caroline.wesson@wlv.ac.uk (C.W.); c.fullwood@wlv.ac.uk (C.F.)

* Author to whom correspondence should be addressed; E-Mail: d.chadwick@wlv.ac.uk; Tel.: +44-01902-323-534; Fax: +44-01902-322-714.

Received: 15 March 2013; in revised form: 11 May 2013 / Accepted: 19 June 2013 /

Published: 17 July 2013

\begin{abstract}
This review gives an overview of the societal inequalities faced by people with intellectual disabilities, before focusing specifically on challenges people face accessing the Internet. Current access will be outlined along with the societal, support and attitudinal factors that can hinder access. Discussion of carer views of Internet use by people with intellectual disabilities will be covered incorporating consideration of the tension between protection, self-determination and lifestyle issues and gaining Internet access. We will address how impairment related factors may impede access and subsequently discuss how supports may be used to obfuscate impairments and facilitate access. We will move on from this to critically describe some of the potential benefits the Internet could provide to people with intellectual disabilities, including the potential for self-expression, advocacy and developing friendships. Finally, strategies to better include people with intellectual disabilities online will be given along with future research suggestions.
\end{abstract}

Keywords: intellectual disability; Internet access; digital divide; support; inequalities; universal design

\section{Introduction}

Information and communication technologies (ICT) have become a crucial aspect of community living and participation. Developments in ICT, with the Internet at the forefront, are profoundly 
changing the knowledge, service, employment and social interactional opportunities available to people with disabilities [1]. In this review we will explore the inequalities and empirical evidence base surrounding the use of the Internet by people with intellectual disabilities (ID).

The commonly used diagnostic criteria for ID, incorporates cognitive, behavioural and developmental components. According to the ICD-10 and DSM-IV for a classification of intellectual disabilities to be given a person firstly must have lower than average intelligence, identified by an IQ score lower than 70. Levels of cognitive impairment have been related to different ID labels: Profound IQ < 20; Severe IQ 20-34; Moderate IQ 35-49; Mild IQ 50-69; and Borderline intellectual functioning 70-84). This should also be coupled with limitations in adaptive functioning in at least two areas (i.e., communication, self care, domestic skills, social skills, self-direction, community, academic skills, work, leisure, health and safety), and an onset prior to age 18 [2-5].

People with ID represent a significant subgroup within the population, most of whom require support of some kind. People with ID are extremely heterogeneous, with complex aetiologies, presentations and often comorbidity. For example, physical (20-30\%) and sensory impairments (10-33\%) often exist alongside their primary cognitive, functioning and developmental impairments [6,7].

Though the definition of ID remains deficit-focused, it has been tempered over the past decade with acknowledgement that ID is a socially constructed term, historically and culturally bound, which is used to label a particular group of people within society [8]. Alongside this there has been a move towards acceptance, tolerance, inclusion and human rights, with significant efforts, occurring in more developed countries, since the 1980 s to remove the societal barriers people with ID face [9]. More recent thinking around disability indicates that the identification of deficits should be integral to the identification of necessary support people require to overcome these challenges and that people's strengths should also be highlighted [4]. In tandem with this growing acceptance of disability, has been a growing societal expectation of ability amongst its members [9]. The world is rapidly changing and becoming an increasingly complex place, requiring greater skills to negotiate it effectively.

\section{Societal Inequalities Faced by People with ID}

Diagnosis with the label intellectual disability can result in life-long labeling, stigma and societal discrimination and restriction of human rights [10-13]. The label of ID is so visible and strong that it often is the primary identity a person has, overriding consideration of other social identities, for example, gender, sexuality and ethnicity $[14,15]$.

Despite their heterogeneity, there remain some common negative consequences of having this identity, centering around societal disadvantage, inequality and prejudice which lead to social exclusion, increased vulnerability and reduced life opportunities. People with ID are socio-economically poorer and more likely to be living on limited or subsidized incomes and in more deprived socio-economic circumstances than the general population [16,17]. They are also more likely to be unemployed, have fewer employment and educational opportunities [3,17], are more likely to be the victims of crime, abuse and bullying [17-20], experience fewer and less satisfying social relationships [21] and have limited social and community integration opportunities [17,22].

Cross culturally, public awareness, understanding and concern for those with ID, appears limited. Misconceptions about the capabilities of people exist alongside aetiological attribution blaming of the 
individual with ID or supernatural forces [23]. Thus, despite the push for inclusion and acceptance, research has revealed that, though improving, attitudes held by the general non-disabled population can still be negative [24]. Also, illustrative of the stigmatisation of this group is the quickly changing nomenclature used, often because prior labels have evolved into terms of derision. Sinason (1992) [25] argues that this may be symptomatic of a defensive need within society to ignore the damaging and painful impact such derision could have on people's lives. Though people may not understand the stigma laden terms used to label them [26,27], experientially and affectively they may understand the label of ID and the stigma and emotional pain attached to this identity [26,28,29]. Here we have chosen to use the term 'people with intellectual disabilities' as this is the dominant terminology currently used within the UK (e.g., [4,10,12,23]). In this review we gathered existing literature to address the following questions: (i) To what extent do people with ID access the online world; (ii) What factors impede and facilitate Internet access; (iii) What are potential benefits to people with ID of being online; and (iv) What can reduce inequalities and facilitate Internet access for those with ID?

\section{Methodology}

For this literature review a search in the Web of Knowledge and PsycINFO databases was conducted in October 2012 (Search dates ranged between 1987 until 2012). All English language papers containing the terms "Intellectual disability" or "learning disability" and "Internet" or "Online" or "Web" in the title or abstract were identified (Note: the search engines also identified and included related terms in the searches). The titles of these studies $(\mathrm{N}=697)$ were then inspected to ascertain whether they were likely to contain information, which could aid in answering the questions developed for this review. The authors subsequently identified and reviewed 43 English language studies focussing on Internet by people with ID for information regarding questions (i) to (iv). Additional resources were found by looking through the reference sections of these papers and through prior knowledge and personal communications with colleagues working in related fields. Contextually and due to the literature gathered, this paper is written from a UK perspective, but also incorporates research from North America, Asia, Australasia and other parts of Europe.

\section{Internet Access for People with ID}

ICT can be viewed as a survival tool in society. Ever increasing numbers of people are going online to conduct many of their everyday activities, including education, business and banking, information searching, seeking of employment, civic engagement, maintaining friendships and seeking life partners [30-32]. Thus, being digitally connected is increasingly fundamental to economic and education advancement and community participation [30]. No longer is access to the Internet considered a luxury, instead it is an integral and important life survival tool which can make life more enjoyable and empower individuals [30]. Although many of us may take for granted the perks associated with Internet access, for certain groups of people the Internet has the potential to help them to better integrate into society and experience many of the benefits of full citizenship. For individuals with ID for example, the Internet promises to decrease or remove many of the barriers which may preclude them from participating in many daily activities [31,32]. However, although people with ID 
potentially stand to gain the most from this technology, they are traditionally the group within society least likely to gain access to and receive the full benefits from the Internet. This clearly mirrors the inequalities people with ID face in other spheres within their lives.

Although it is evident that a "digital divide" exists between societies and within society, it is difficult to know for sure exactly how many people with ID are actually accessing the Internet, and of those who do gain access, what they find particularly beneficial or useful. The majority of large scale studies on web accessibility have focused on disability generally. For example Fox (2011) [33] noted a "disability divide" in Internet access in the United States, with $81 \%$ of the non-disabled population gaining access compared to only $54 \%$ of disabled individuals. A recent US report revealed a considerable disparity between households headed by someone with a disability and those headed by someone with no disability in computer ownership (53\% vs. 79\%), Internet use (48\% vs. $76 \%)$ and broadband adoption (46\% vs. 73\%) [34]. An even greater disparity was revealed in a 2007 British survey, with $77 \%$ of the non-disabled population using the Internet compared to $36 \%$ of disabled individuals [35]. A more recent UK report suggested people without disabilities are three times more likely to have never accessed the internet compared to people without disabilities [36]. The report also indicated that 3.89 million people with disabilities (33\%) had never accessed the Internet [36]. Finally, a recent smaller study of 122 disabled individuals in China, confirmed the digital divide that exists, with only a minority of people with disabilities having Internet access [37]. As these surveys have failed to discriminate between physical and intellectual disabilities, it is difficult to ascertain how specific types of impairment may influence use and access to the Internet [38,39]. Moreover, such studies sometimes fail to draw a distinction between opportunity of access and actual use of the Internet. In this sense, two distinct questions should be posed: are opportunities for access available to individuals with ID (i.e., do they have access to a computer that is enabled for use online), and if they are, do they actually take advantage of these opportunities, either autonomously or with support? [38].

Of the few studies that have addressed Internet accessibility specifically in the ID community, most have found that people with intellectual and developmental disabilities are much less likely to have access to and use the Internet than their non-disabled peers. In a small scale survey of 83 adults with intellectual disabilities in the United States for example, Carey et al. (2005) [40] noted that a mere $41 \%$ had access to a computer and only $25 \%$ had access to the Internet. In the same year, approximately $68 \%$ of the total population of America had access to the Internet [41], illustrating an apparent disability divide in Internet access. A larger scale study of 156 adults with ID in Spain revealed that $53 \%$ did not access the Internet at all [42]. As a way of comparison, only $37 \%$ of the total Spanish population did not access the Internet in 2010 [43]. Moreover, only $6.4 \%$ of those with ID reported using the Internet from places outside of their home and of those who did access the Internet, over half (56.4\%) reported that they did not use the Internet regularly [42].

Studies requesting access information from carers have also been conducted. One exception to the general consensus is a study that looked at Internet use amongst children and young people with Down syndrome based in the USA by surveying 561 of their carers [44]. In this survey the vast majority of younger people were found to use the Internet for either learning or entertainment. In Palmer, Wehmeyer, Davies and Stock's (2012) [45] survey of 1617 family members of people with ID in the United States, whilst $43 \%$ of people with ID who had access to a computer used this to access the Internet, half of the respondents indicated that their family member did not have access to a computer 
in the first place, despite feeling that it would be of benefit to them. Studies also suggest that even if Internet access is available it may not be used. For instance, Gutiérrez and Martorell (2011) [42] found that although $50 \%$ of people with ID had an Internet connection in their family home, $25 \%$ of these individuals never used the Internet at all.

Currently, it appears that although there are problems in disaggregating people with ID within the literature, the general population have greater access to the Internet than people with disabilities generally, there is also some anecdotal suggestions that perhaps people with other types of disability have greater access than those with ID. However, more information is still required about the prevalence and nature of Internet use by specifically people with ID. In particular it is important that future studies report more clearly the nature of the impairments of respondents, as noted people with ID are a heterogeneous group and so Internet access and influences on access are likely to differ amongst them. Furthermore comparisons of Internet access across disabled groups with different types of impairments should be made. Such studies would help to illuminate specific supports required by different groups and illuminate why, though the Internet is available, it is not always used. Empirical evidence that people with ID are discriminated against in terms of Internet use is also lacking. In the subsequent sections we will consider factors that can impede or enhance online access for those with ID.

\section{Barriers to Internet Access for People with Intellectual Disabilities}

It appears that the majority of people with ID are not accessing the Internet to the same degree as others and that not all of those with ID that have access to a computer and Internet access actually use it. We now turn to the barriers and challenges that have been implicated in the reduced access that people with ID experience.

\subsection{Financial and Economic Barriers}

Due to its role as a means of information gathering and sharing, use of ICT corresponds to having increased power and control within society. The digital divide draws attention to how disempowered groups with limited economic resources have reduced access to ICT. Empirical evidence from self-report studies confirms that economic factors play a role in Internet access. For people with ID, who are typically more economically disadvantaged, cost is a commonly mentioned barrier to computer, and in turn, Internet access [32]. This can reflect an inability to finance purchase of a computer and hence gain access within the family home [45-47] or within a residential unit or day care centre [48-50]. Thus access to ICT becomes an issue of social justice, with these two factors (economic disadvantage and barriers to information access) interacting to exacerbate oppression.

\subsection{Societal Attitudes and Exclusion}

However, barriers to access are not always necessarily a consequence of financial constraints (i.e., insufficient funds to purchase a computer and pay for Internet access). With regard to social attitudes, the accessibility requirements of people with ID have often been disregarded or misunderstood. One reason for this, as noted earlier, is the invisibility of this group to the general 
population [51]. Wehmeyer et al. (2004) [52] argue that computers are 'cognitively inaccessible' for many individuals with ID and that this may be due to this group of people having rarely been included in decisions relating to computer design. Indeed, Goggin and Newell (2003) [53] claim that people with disabilities are rarely found in positions of power in organisations that make decisions on Internet policy and for this reason the digital divide will continue to expand. In Palmer et al.'s study (2012) [45] $13 \%$ of respondents identified device complexity as a barrier to Internet use. In order to ensure that people with ID can make use of the Internet further development of universal design principles are imperative.

\subsection{Policy and Governmental Support}

Despite the existence of numerous legislative imperatives and societal obligations to promote inclusion and full citizenship of people with ID (e.g., UNCRDP, 2006 [54], Equality Act, 2010 [55]), these do not appear to have manifested in real attitudinal change or in action based work to promote access to ICT, including the Internet, for people with ID. Universal design incorporates "the design of products, environments, programmes and services to be usable by all people, to the greatest extent possible, without the need for adaptation or specialised design" [54] and is not apparent in the vast majority of websites that have been studied [56,57]. There seems to be a lack of strategy around how to include people with ID further, and although legal penalties have been noted as a route to promoting compliance, implementation of such penalties is lacking [57].

\subsection{Support, Educational and Training Barriers}

Support is essential for most people with ID to engage with Internet [58]. Training and ongoing support for Internet use is typically provided by family carers and direct support staff [46]. Undoubtedly a lack of suitable support and training can limit people with IDs' ability to use a computer [40,59] and Internet access for people with severe ID can be a challenge and for some viewed as unsuitable $[32,60]$. However support may be inadequate or absent in some instances and the expertise of family carers in Internet use may interact with support requirements, beliefs and expectations to thwart access by people with ID.

For the families who are providing support, having adequate time and expertise may present barriers to accessing the Internet. In a study of 788 family carers it was found that although many family carers did access the Internet, a significant proportion did not [61]. Balancing other commitments with those of supporting the people they support to get online may also be challenging for family carers and paid staff [50,61]. Moreover, a lack of skills and technical expertise has been highlighted by family carers as issues in their own Internet use [61]. Similarly, for paid supporters, facilitating Internet access will require adequate staffing levels and skills which are not always available or present. The majority (84\%) of respondents in Palmer et al.'s (2012) [45] survey identified training as a barrier to use. Moreover, Blackburn et al. (2005) [62] in their survey based study suggest that family carers need additional education regarding the technology options available to them and in how to use technology related supports to enable people with cognitive disabilities to access them. Thus the resources and skills of carers require further investigation and intervention. 
With regard to education of people with ID to access the Internet, few studies that have mentioned this or report on interventions to improve the skills of people with ID to utilize ITC. Those that have been conducted suggest that mentoring and training programmes can be beneficial in promoting access, which will be discussed later. Guo et al. (2012) [37] found that disabled people with higher levels of education are more likely to have access to the Internet. Though this finding may be confounded with level of cognitive impairment, and type of impairment was not distinguished in the study, this does suggest that education and knowledge of the Internet may a fundamental factor in promoting or hindering Internet access for those with disabilities. Education is likely to interact with age, with more educational and online opportunities being made available to younger people with ID than older people with ID [63].

In addition to caring responsibilities, education, training and expertise, carer attitudes and organisational culture have also been found to be important influences on Internet access. As noted earlier, Gutiérrez and Martorell (2011) [42] found that only 25\% of people they surveyed with ID who had access to the Internet used it and suggest that this is because Internet access is blocked by parents and caregivers who foresee more problems than benefits in facilitating access. Seale (2007) [64] highlights how protection and fears about online safety may impede online access and engagement.

Löfgren-Mårtenson's (2008) [65] qualitative study exposed a discrepancy between the views of the young people interviewed and those of the staff members regarding the advantages and disadvantages of the Internet. For the young people, not surprisingly, a positive view was generally taken to the Internet in contrast to the mostly pessimistic view of the staff who, for the most part, saw the Internet as being unsuitable for people with ID due to the risks involved. Their views on risks seemed to be based on how the Internet is presented in the media, and on preconceptions about people with intellectual disabilities who were considered to belong to a vulnerable and exposed group. Younger staff members had a more positive view of Internet use by people with ID, seeing it as advantageous.

Parsons et al. (2008) [63] argue that the extent to which service providers hinder or facilitate Internet access for people with ID is due to organizational culture and the attitudes of staff concerning the use of ICT, including Internet access. Family and paid carers may believe that: (i) the Internet is beyond the skills of people with ID and hence is inappropriate for them to use; (ii) the Internet is itself creating a barrier to social inclusion and interpersonal interaction; (iii) ICTs are purely educational and literacy based tools that are inappropriate for the people they support with ID to use; and (iv) ICT is inappropriate for older people with ID and those with more significant cognitive impairments. Such attitudes may be especially prevalent amongst older carers who are themselves less likely to access the Internet [66]. Therefore they will not provide necessary supports for people with ID to access the Internet. However, despite some residential and day centres being supportive of computer use for people with ID, their communication via this means rarely involved people outside of these facilities and instead support focused primarily on tasks localised within the support setting [50]. Thus this represented an ongoing barrier to full integration into the mainstream digital world.

The limited empirical evidence that exists demonstrates a need to look beyond simply providing ICT equipment, to the contextual factors that impact on training and support, including the views, experience and skills of support staff and family carers. Further research work and organisational commitments to facilitating carer expertise, belief and investment in the Internet are needed. 


\subsection{Individual Impairment Associated Challenges in Accessing the Internet}

At an individual level, there are a number of cognitive, physical and sensory impairments associated with intellectual and developmental disabilities that will make accessing and using the Internet more challenging. Barriers to Internet access and use may reflect a interaction between the literacy, language and processing demands of using the Internet with impairments in language and communication ability and auditory reception, reasoning, idea production and cognitive speed, memory and learning skills, visual perception abilities and knowledge and achievement abilities [52].

As the primary input mode for the majority of Internet based communications (e.g., e-mail, instant messenger) involves typing, impairments in language and communication ability may prevent individuals with ID from getting their thoughts across in a way that is easily understandable to others [52,67]. As the majority of communications in the online world rely on text input, this also means that many of the nonverbal communication cues that may be used to infer meaning in a message (particularly relating to emotions and interpersonal attitudes) will be missing or seriously attenuated, adding an additional layer of difficultly for co-communicators [38]. Moreover, as the majority of the information contained on the web is also text-based, accessing and using this information could pose problems for those individuals with impairments that affect literacy and reading comprehension. Wehmeyer et al. (2004) [52] also consider how much of the terminology that is used in the world of computers and the Internet may be confusing to individuals with ID. For example, terms that have multiple meanings (e.g., menu, files, folders and window) may present problems to individuals with an ID, who can find abstract concepts more difficult to comprehend than concrete ones [27].

Using the Internet requires a level of sequential reasoning. For example, navigating the Internet is complex and interactive and the user must understand that specific actions are required in order to lead to desired responses. There must, for instance, be an understanding that all the information that one requires will not necessarily be contained within one specific webpage and that a number of steps may be required to access what one needs. Websites that require individuals to memorize long sequences of commands to get to where they want to go may put people with ID at a distinct disadvantage. Certain elements of website interface may interfere with the user's ability to reason abstractly. For example, cognitive impairments may impede one's ability to comprehend that a computer cursor arrow transforms into a hand icon when passed over a hyperlink or to differentiate successfully between the actions performed by a single click, right click or double click of the mouse [52]. Impairments in cognitive speed may specifically come to the fore if web connectivity is slow as this will mean that making a connection between the actions performed by the individual (e.g., clicking the mouse button) and the subsequent computer response may be difficult to achieve. Individuals with ID may also be hindered by an inability to recognize when one is required to wait for a webpage to catch up, which may result in errors in the form of multiple clicks because the individual cannot understand that the initial click of the mouse was sufficient [52,67].

In terms of visual perception abilities, intricate displays with numerous screen elements, windows and buttons may pose problems to those who find attending to relevant environmental cues a difficult task to accomplish [52]. Websites are rarely designed to meet the needs of individuals with intellectual and developmental disabilities [53], and simple interfaces may be necessary for many individuals with ID to navigate them successfully [68]. Another issue relates to the current dominant mode of 
interfacing with the Internet (i.e., by making use of point and click devices, e.g., the mouse). Users need to make an association between the movement of the mouse and the corresponding movement of the arrow on the screen. Therefore, correlating hand movements with arrow cursor movements on screen is an essential component of Internet interface, and impairments in motor skills and visual perception abilities may make this task complex [52].

It would seem then that computers and websites are not set up in a way that would make using them straightforward for people with ID and therefore a lack of experience and necessary skills to access and utilise computers and the Internet may be one major barrier to access. Bunning et al. (2009) [69] found that some people with ID expressed difficulties using ICT related to operational aspects of the technology. The severity of cognitive impairment is also likely to be a key consideration. Individuals with mild-moderate cognitive impairments have been reported to be more frequent Internet users [42,65]. However, individuals with severe and profound disabilities tend to be overlooked when it comes to Internet access [32] with the assumption being that these individuals are not capable of utilising the Internet. For these people physical access difficulties, visual impairments and cognitive limitations restrict what may be gained from the Internet. Moreover, though the Internet may be utilised towards the advancement of people with profound intellectual and multiple disabilities, those who do not operate at a symbolic level of communication and understanding are less likely to be able to engage meaningfully with the Internet even with support $[60,70]$.

To summarise, there would appear to be a number of barriers which not only prevent individuals with ID from gaining access to the Internet in the first instance, but also in making using the Internet a more onerous task when access can be achieved. Financial and economic barriers appear to be the most commonly cited reason for not being able to access the Internet [32,45-50] and although free access in public libraries may go some way towards addressing this, this will be of little use to those individuals whose impairments, coupled with insufficient support, means that leaving the house is problematic. Government initiatives to address the digital divide (e.g., [57]) may be necessary to ensure that this often economically under-privileged group are able to get online and receive the full benefits of digital inclusion. Although a number of positive, exciting projects have started to address how specific impairments which affect internet use and access may be compensated for (some of these are outlined in section 7 of this paper), few initiatives have sought to address the negative attitudes that are held by many support workers and carers regarding the Internet [63-65]. The fact that many support workers perceive the Internet as a dangerous environment or one which may not be suitable for people with ID may suggest the need to educate or raise awareness amongst carers about the potential benefits of being online for the people with ID. What is also clear is that further research should focus on the manner in which specific impairments impact upon access and use of the Internet $[32,52,69]$. To date, most research in this area has considered the ID community as a very homogeneous group and certainly one would expect that the type and severity of one's impairment will be crucial in determining the specific types of support, intervention and training that are necessary to help someone get online and use the Internet safely and effectively. 


\section{Potential Benefits of Internet Use for People with Intellectual Disabilities}

The compensation model has been utilized to explore the impact of the Internet on marginalized populations including those with disabilities [66]. Under this model those who are socially inactive or dissatisfied with their existing real world social interactions tend to use the Internet more frequently, subsequently benefitting more from their Internet use [71]. However, the Social Model of Disability [72] may have greater explanatory power by highlighting the environmental barriers to Internet access and how the power of the Internet lies in its potential to alleviate attitudinal, geographical and physical barriers to social exchange. Nonetheless it is also important not to overlook individual voices and needs and the role of impairment in Internet use, which the social model has been accused of doing [73]. Some research in this area has included the voices of people with ID about the benefits they have experienced. Access to the Internet can provide a wealth of opportunity for people with ID, opening up avenues for self-determination, learning, entertainment, self-expression and socialisation [32]. In terms of self-expression, the Internet affords an opportunity for people with disabilities, including ID, to present themselves outside of their disability, having the option to disclose, or not, their disabled identity at will $[38,65,74,75]$.

\subsection{Online Social Relationships}

Research evidence has considered the challenges people with ID face developing meaningful friendships and relationships [17,21,22]. The difficulties that people with ID experience in terms of communication can get in the way of developing friendships, and people with ID may experience feelings of loneliness [76]. Being able to communicate with a wider audience means that engaging with social media may have the potential to reduce feelings of loneliness for people with ID [77]. Guo et al. (2005) [37] found that for the minority of disabled people with access to the Internet, this significantly improved frequency and quality of social interaction and they suggest that the Internet significantly reduced existing social barriers in the physical and social environment for disabled people.

Löfgren-Mårtenson (2008) [65] sees the Internet as providing possibilities of a private life for people with ID, a life away from the control of their carers. The individuals in her qualitative study of Internet usage by young people with mild ID in Sweden reported that the Internet allowed them freedom, being able to decide which websites to visit and who to communicate with. Their primary usage of the Internet was found to be for social and romantic purposes. The perceived vulnerability of people with ID has led to the creation of safer social networking environments for people with ID [65]. However, reporting on the social networking experiences of people with ID, Holmes and O'Laughlin (2012) [78] found that respondents did not necessarily want to use such restricted social networking sites, preferring to have access to social networking sites that allowed for interactions with a wider audience, an audience not restricted to those with ID.

Burke, Kraut and Williams (2010) [79] found that 16 high-functioning adults with autism when observed and interviewed sought greater social connectedness and utilized communities with shared interests and fostered successful, supportive relationships. However, despite these positive findings they also found that, amongst the participants, computer mediated communication intensified difficulties around trust, disclosure, inflexible thinking and perspective taking, which in turn impeded maintaining 
online relationships. Clearly more work is needed to identify the facilitators and challenges to engaging in and maintaining meaningful online relationships for people with ID, which also considers the heterogeneity of this group of people.

\subsection{Expressed Identity and Reducing Stigma}

Having support to go online may help people with ID to cope with the negative stereotypes, attitudinal biases, and social and physical exclusion that are viewed as potential risks and can impede access. Shpiglman et al. (2008) [80] conducted a small scale qualitative pilot evaluation of a 3-month e-mentoring programme for young people with special needs, including mild to moderate ID. In the programme mentors acted as a friend and advisor, providing instrumental and psychological support and encouragement to five teenage pupils with special needs. This mentoring was mainly online rather than face-to-face, and the students with special needs commented that they would have liked more face-to-face support. Nevertheless the online medium rendered their disabilities invisible and made them feel like 'typical teenagers'. The students had developed their interpersonal skills and teachers reported on potential generalization of social skills, with those mentored developing more meaningful relationships with classmates, being more sensitive and considerate towards special needs and appearing to have increased positive self image and self-esteem.

Other studies have also commented on the potential of the Internet for allowing people with ID to reduce the stigma they experience by being visually anonymous [81]. In terms of social relationship development this may impact greatly as physical appearance can have a substantial impact upon first impressions and subsequent relationship formation [82]. However, it has been argued that the Internet may not be the emancipatory landscape for disabled people as has been claimed [75] and Bowker and Tuffin (2003) [74] state that hiding ID is likely to do little to reduce the stigma or increase the acceptance of people with ID within society.

\subsection{Self-Determination and Advocacy}

With regard to increased life opportunities for people with ID, the Internet has also been found to be successful in reducing physical barriers to education and learning with respondents reporting receiving long-distance education via the Internet [37]. Moreover, online activities, for instance home page authorship, have been seen as providing an opportunity for people with ID (specifically in these cases DS) to counter the oppression they face in their lives, allowing them to challenge perceptions of their competencies and also the labels they have placed upon them by society $[64,83]$. However, Seale (2007) [64] observes that this capacity to stand up against oppression via the Internet is controlled by those who act as gatekeepers to the individual's access to the Internet, with caregivers shutting websites down for fear of exposing the individual with ID to prejudice they may face as a result of their public challenges to oppression. Controlling the hosting and authorship of said homepages goes some way to protect against this, but raises questions regarding the extent to which these homepages are actually empowering for the individual with ID. Indeed, Seale (2007) [64] states that the online safety of individuals with ID is so closely guarded that this may limit the capacity for self-advocacy. Seale (2007) [64] raises the question of whether homepage authorship by people with ID is interdependent with or dependent on the parent supporting the authorship. 
The potential of the Internet has yet to be fully realized; however the possibilities for increased social contact, reducing stigma and identity development, and increasing life opportunities to practice self determination and self-advocacy are evident. Nevertheless, most studies that have been conducted in this area have tended to focus on those with physical disabilities, thus less is known about those with ID. The lack of research around these potential benefits is likely to be a direct result of the limitations and inequalities in access that people with ID experience. Moreover, the anticipated benefits are not without challenges with points of contention and risk inherent within them that warrant further empirical exploration.

\section{Reducing Inequalities}

The benefits of the Internet are apparent and challenges and barriers to this access have been identified in the literature. Early guidelines for making the Web more accessible to people with disabilities concentrated primarily on people with physical disabilities. Only more recently has there been some acknowledgement that intellectual impairments often go hand-in-hand with physical disability (for example acquired brain injury) and that people with ID have been generally overlooked in terms of Internet access. Overcoming access barriers requires action on a number of fronts, with empirical evidence suggesting possible routes to reduce inequality in Internet access via support solutions to address impairments, educate and train people to facilitate access and modify attitudes that may serve to impede access.

\subsection{Supporting Impairments}

A number of potential solutions have been put forward to address cognitive, physical and sensory impairments and to help individuals with ID to adapt to the Internet so that it is more accessible. Establishing whether individuals with ID are capable of interacting with Internet interfaces is no mean feat. As noted, Wong et al., (2009) [60] even go as far as to suggest that many individuals with more severe or profound intellectual disabilities may not be suited to computer use at all. The potential benefits of using the Internet therefore need to be weighed up against the level of difficulty associated with going online as well as the support requirements and level of adaptation that would be necessary to allow an individual to use the Internet in a meaningful way. Wong et al. (2009) [60] suggest that training should be tailored to meet the individual support requirements and primary functioning impairments of the individual. Understanding the specific impairments of the individual is essential to understand which areas of support and adaption are required. Support would seem to be an essential element in the successful interface between the individual and the technology. Indeed, Reimer-Reiss and Whacker (2000) [84] acknowledge that the assistance of support workers is a key ingredient in ensuring that users continue to use technology and regard it as effective. Furthermore, it has been suggested that given the appropriate support and structure, the majority of adults with mild to moderate ID can use the Internet in its current form without the need for specialized adaptation [67].

Although suitable for the general population, a simpler Internet interface is likely to be necessary for many people with ID, and indeed this would seem to be a common concern for parents, caregivers and teachers alike [68]. As Dawe (2006) [68] notes, individuals with ID are not as likely to use the Internet a second time if their initial experience was unenjoyable or fraught with difficulty. Addressing 
issues of adapting the Internet to meet the needs of the ID community, Universal design principles are a fundamental concern. Universal design is critical in allowing people with ID to gain substantial benefits associated with being online. There are a number of principles associated with Universal design and these all affect user interface with the webpage. For example, websites should be flexible, simple and intuitive, contain perceptible information, include tolerance for error and require low physical effort [85]. Wehmeyer et al. (2004) [52] discuss how many of these principles may be particularly relevant when considering the limitations of people with ID in their use of technology. For instance, websites that are more flexible should accommodate a wider array of user preferences and abilities, for example by providing multiple input and output options (e.g., auditory, visual, icon). Intuitive and simple interfaces should used, for example websites should have a limited number of options so as not to overwhelm the user. Moreover, there should be a single intuitive means of achieving a desired goal rather than many ways of accomplishing the same task (e.g., one link to a page, rather than multiple links) [52]. Unfortunately, at present few websites actually conform to the principles of universal design and web designers have limited understanding of how websites can be made more accessible to all [51].

A number of more innovative solutions to Internet inaccessibility have also been proposed. For example, Wehmeyer et al. (2004) [52] note that touch screen interfaces (e.g., tablets) may be better alternatives to point and click options because it would be easier for the individual to see a cause and effect relationship between action (i.e., pressing the screen) and reaction (i.e., taking the individual to the desired web page). Addressing impairments in language and communication ability, Keskinen, Heimonen, Turunen, Rajaniemi and Kauppinen, (2012) [86] report on the efficacy of a picture based instant messenger service called SymbolChat. The fully customizable software is based on touch-screen input and speech output. The prototype application was evaluated by nine adult users with varying degrees of ID and their support workers. Findings suggest that users can express themselves in spontaneous communication even without prior training in the use of symbols. This suggests that although much of the web may be off limits or will require a high level of adaptation or support to use, specialized software can be designed to effectively meet the needs of the ID community. The World Wide Web Consortium (W3C) represents a promising initiative, underpinned by policies such as the UNCRDP, and has been working extensively around providing more evidence and guidance around how to include people with disabilities in the online world [87]. The consortium, when updating standards (the Web Content Accessibility Guidelines [88]) to include those with cognitive impairments, did encounter challenges in defining and considering this group due to the range of conditions contained within it and the diversity of support needed. Nevertheless they have developed a number of strategies web designers can employ to support online access for this group, broadly including:

"Text alternatives for non-text content;

Captions and other alternatives for multimedia;

Content can be presented in different ways;

Content is easier to see and hear;

Users have enough time to read and use the content;

Content does not cause seizures; 
Users can easily navigate, find content, and determine where they are;

Content is readable and understandable;

Content appears and operates in predictable ways;

Users are helped to avoid and correct mistakes;

Content is compatible with current and future user tools." [89]

However, empirical testing of the utility of such strategies, though anecdotally supported, is by and large absent for those with ID.

\subsection{Support Strategies}

From the preceding discussion it appears that the nature of computers and websites do not currently facilitate access for people with ID [69], but despite this, support can enable online access. At the most basic level, instruction in simple computer skills (e.g., how to use a mouse or navigate a webpage) can facilitate Internet usage for people with ID [32,39,90]. Identifying online needs is also important. Accessing the Internet can be a frustrating exercise for people with ID when they have difficulty in locating websites of interest or the information that they require. Maintaining motivation is important; guided Internet sessions have been found to be helpful here with supporters identifying the information individuals require and structuring the session accordingly [67,91].

Examples of empirical work to develop online skills and opportunities are also evident in the literature. Li-Tsang et al. (2004) [92] have demonstrated the effectiveness of a training programme in the use of ICT for people with ID. Their findings indicate that people with ID have the ability to learn basic ICT skills if they are placed in a structured environment with appropriate training tools and assistance. Individuals who took part in the specialised training program made significant improvements in their ICT skills (e.g., mouse and keyboard use) comparative to a control group. Mentoring people to promote Internet access also has empirical support for its potential in increasing online skills and confidence. Shpiglman et al.'s (2008) [80] evaluation of an e-mentoring programme for young people with special needs, found that the students who had been mentored, in addition to other social benefits, reported learning a great deal about how to use the Internet. Assisting with the authorship of online content is another area in which carer support can facilitate Internet access. Seale (2007) [64] found that the Home pages of people with Down Syndrome in her study were frequently published as part of a family site, appearing alongside those of their parents or siblings. Family support came in the guise of home page authorship itself, with some of the pages appearing to have been written by, or at least co-authored, by the family member of the individual with ID on behalf of the individual.

Thus evidence suggests that even though accessing the Internet is difficult for people with ID it is not impossible and with the appropriate support and guidance adjustments can be made to facilitate access and obfuscate impairments [93]. However, it is important that those providing training and support are appropriate to the task and that family and paid supporters are given adequate time, training and resources to support appropriately. Unfortunately evidence suggests that caregiving responsibilities and inadequate staffing and staff training may be the norm [50,63]. Paid staff would likely benefit from protected time in which they can carry out developmental ICT related activities with those they support with additional orientation towards using the Internet to access the wider online world. Moreover, there remains a general lack of information about which supports improve 
the use of ICT by adults with ID in post education support environments where developmental opportunities are likely to diminish [50,63].

\subsection{Addressing Attitudes}

Finally, little is likely to change in terms of Internet and ICT access for people with ID until attitudinal barriers are tackled. At a societal level fear may underpin much of the manifest negative attitudes towards people with ID, which result in this group being overlooked and seldom considered in relation to societal developments such as those seen in ICT. It is unlikely that this situation will change without advocates and self-advocates from the ID community coming forward to raise awareness and maintain political pressure for real change in how the online world is developed and who it is viewed to be for. Tangible ramifications for national transgressions of the obligation for websites to be inclusive and embrace universal design principles may also be required. To facilitate a move towards universal design, an attitudinal shift is required among those in positions of power, so that they begin to demonstrate a commitment to accessibility on the web and to understanding the needs of ID audiences [94]. Public information and communication campaigns and socio-political action may be fundamental routes by which this can be achieved, whereby the attitudes of those in positions of influence may be changed which may subsequently lead to inequities being redressed.

Considering more localized attitudes which operate at the level of individualized support, Parsons et al. (2008) [63] found that progressive, person-centred approaches to the day centre provision were actively supportive of the use of ICT, including Internet access, with people with ID, moreso than less person-centred, more traditional services. In settings where the Internet was more often used by people with ID, the carers were more likely to view ICT as an important inclusion and communication facilitation tool that can be used with anyone. Organisational culture highlighting an understanding of the potential uses of ICT and training staff towards these uses is an important means to increase access and address negative attitudes. The lack of studies around attitudinal change within this area reveals that much more work is needed to investigate more fully the relationship between attitudes and Internet access facilitation, and ultimately how such access impacts on the lives, skills and social capital of younger and older people with ID.

\section{Conclusions and Future Directions}

Evidence presented here suggests that that people with ID are not accessing the Internet to the same degree as others within society. Advances in computer technology have largely bypassed individuals with ID, particularly adults with severe impairments. Their functional variations and impairments, the education, training and supports they receive, and wider political, economic and attitudinal climate can combine in complex and varied ways to marginalize people with ID from accessing the using ICT and, more specifically, the Internet. Statistics on Internet accessibility for people with ID remain limited, and it has been argued that there is a dearth of academic studies which address the disability divide specifically in individuals with ID [51]. More needs to be done to consider what proportion of individuals with an ID actually can access the Internet as well as the barriers which may preclude access. Attitudinal barriers need much further consideration, with a view to altering negative attitudes. 
Issues of safety, risk and protection online for people with ID have yet to be adequately investigated and these currently serve as reasons given for hindering people from gaining online access.

Despite claims that the Internet will bestow benefits, empirical verification of the actual social benefits and development opportunities provided by the Internet for people with ID is lacking. The voices of people with ID need to be included here ( $c f$. [87]), along with well-designed evaluative and comparative research investigating the impact of Internet use on people's lives. Impact on the lifestyles of people with ID, could include investigations of social capital development, social and ICT skill development and opportunities afforded by Internet use. Moreover, our understanding of how to enable people with ID to participate more fully in the online aspects of our society remains limited. The evidence base that does exist points to simplified Universal design for the Internet, improved training and time for carers to facilitate access, building ICT into organisational cultures and addressing carer and societal attitudes to people with ID and to such people accessing the Internet. Existing theories, including the nested ecological model and Capability theory $[95,96]$, could help guide empirical endeavors aimed at identifying contributing factors and poverty and disadvantage. Such theories may help to shed light on the impact of broader societal macro drivers in injustices, and on more micro interactional aspects of inequality and opportunity, including the individual's impairments, and how these interact with supports to affect the capability and subsequent agency in engaging with the online world. Thus the research possibilities, and the impact application of such research could have on the lives of people with ID appears manifold. Though potential impacts are unlikely to occur unless the research endeavour incorporates dissemination and implementation strategies and actions aimed specifically at producing change.

In sum, Internet use, which has become such an integral part of the daily lives of people around the world, is a further part of life that people with ID appear to be fundamentally excluded from. So for people with ID, the promise of the Internet is far from being fully realized and the advocacy and academic community, in collaboration with people with ID, are needed at the forefront of the struggle for full online inclusion.

\section{References}

1. Ritchie, H.; Blank, P. The promise of the Internet for disability: A study of on-line services and web site accessibility at centers for independent living. Behav. Sci. Law 2003, 21, 5-26.

2. American Psychiatric Association (APA). Diagnostic and Statistical Manual of Mental Disorders, 4th ed.; American Psychiatric Association: Washington, DC, USA, 1994.

3. Valuing People: A New Strategy for Learning Disability for the 21st Century; Department of Health: London, UK, 2001.

4. Schalock, R.L.; Borthwick-Duffy, S.A.; Bradley, V.J.; Buntinx, W.H.E.; Coulter, D.L.; Craig, E.M.; Gomez, S.C.; Lachapelle, Y.; Luckasson, R.; Reeve, A.; Shogren, K.A.; Snell, M.E.; Spreat, S.; Tasse, M.J.; Thompson, J.R.; Verdugo-Alonso, M.A.; Wehmeyer, M.L.; Yeager, M.H. Intellectual Disability: Definition, Classification, and Systems of Supports, 11th ed.; American Association on Intellectual and Developmental Disabilities: Washington, DC, USA, 2010.

5. World Health Organisation (WHO). International Classification of Diseases, 10th Revision; WHO: Geneva, Switzerland, 1992. 
6. Hatton, C.; Emerson, E. Services for adults with learning disabilities and sensory impairments: Results of a national survey of Local Authorities. Br. J. Learn. Disabil. 1995, 23, 11-17.

7. McLaren, J.; Bryson, S.E. Review of recent epidemiological studies of mental retardation: Prevalence, associated disorders, and etiology. Am. J. Ment. Retard. 1987, 92, 243-254.

8. Manion, M.; Bersani, H. Mental retardation as a western sociological construct: A cross cultural analysis. Disabil. Handicap Soc. 1987, 2, 231-244.

9. Brown, I. What Is Meant by Intellectual and Developmental Disabilities? In A Comprehensive Guide to Intellectual and Developmental Disabilities; Brown, I., Percy, M., Eds.; Brookes: Baltamore, MD, USA, 2007.

10. Ali, A.; Hassiotis, A.; Strydom, A.; King, M. Self stigma in people with intellectual disabilities and courtesy stigma in family carers: A systematic review. Res. Dev. Disabil. 2012, 33, 2122-2140.

11. Despouy, L. Human Rights and Disability; Doc. E/CCN.4/Sub.2/1991/31; United Nations Economic and Social Council: New York, NY, USA, 1991.

12. European Union Monitoring and Advocacy Program. Report on People with Intellectual Disabilities; Open Society Institute: Budapest, Hungary, 2005. Available Online: http://www.soros.org/ initiatives/health/focus/mhi/articles_publications/publications/romania_20050902/lithuania_2006.pdf (accessed on 11 March 2013).

13. Harris, P. Who am I? Concepts of disability and their implications for people with learning difficulties. Disabil. Soc. 1995, 10, 341-351.

14. Burns, J. Gender identity and women with learning difficulties: The third sex. Clin. Psychol. Forum 2000, 137, 137-139.

15. Walmsley, J.; Downer, J. Shouting the Loudest: Self Advocacy, Power and Diversity. In Empowerment in Everyday Life; Ramcharan, P., Roberts, G., Grant, G., Borland, J., Eds.; Jessica Kingsley: London, UK, 1997.

16. Emerson, E.; Hatton, C. Socio-Economic Position, Poverty and Family Research. In On Families: International Review of Research on Mental Retardation; Glidden, L.M., Seltzer, M.M., Eds.; Academic Press: New York, NY, USA, 2010.

17. Emerson, E.; Mallam, S.; Davies, I.; Spencer, K. Adults with Learning Difficulties in England 2003/4; Office of National Statistics and NHS Health and Social Care Information Centre: London, UK, 2005.

18. Hughes, K.; Bellis, M.A.; Jones, L.; Wood, S.; Bates, G.; Eckley, L.; McCoy, E.; Mikton, C.; Shakespeare, T.; Officer, A. Prevalence and risk of violence against adults with disabilities: A systematic review and meta-analysis of observational studies. Lancet 2012, 379, 1621-1629.

19. Sheik, S.; Pralat, R.; Reed, C.; Sin, C.H. Don't Stand by; Hate Crime Research Report. Mencap: London, UK, 2010. Available Online: http://www.mencap.org.uk (accessed on 11 March 2013).

20. Sin, C.; Mguni, N.; Cook, C.; Comber, N.; Hedges, A. Targeted violence, harassment and abuse against people with learning disabilities in Great Britain. Tizard. Learn. Disabil. Rev. 2010, 15, $17-27$.

21. Chappell, A.L. A question of friendship: Community care and the relationships of people with learning difficulties. Disabil. Soc. 1994, 9, 419-433.

22. Forrester-Jones, R.; Carpenter, J.; Coolen-Schrijner, P.; Cambridge, P.; Tate, A.; Beecham, J.; Hallam, A.; Knapp, M.; Wooff, D. The social networks of people with intellectual disability 
living in the community 12 Years after resettlement from long-stay hospitals. J. Appl. Res. Intell. Disabil. 2006, 19, 285-295.

23. Scior, K. Public awareness, attitudes and beliefs regarding intellectual disability: A systematic review. Res. Dev. Disabil. 2011, 32, 2164-2182.

24. Staniland, S. Public Perceptions of Disabled People: Evidence from the British Social Attitudes Survey; Office for disability issues, HM Government: London, UK, 2009.

25. Sinason, V. Mental Handicap and the Human Condition: New Approaches from the Tavistock; Free Association Books Limited: London, UK, 1992.

26. Beart, S.; Hardy, G.; Buchan, L. How people with intellectual disabilities view their social identity: A review of the literature. J. Appl. Res. Intell. Disabil. 2005, 18, 47-56.

27. Finlay, M.; Lyons, E. Social identity and people with learning difficulties: Implications for self advocacy groups. Disabil. Soc. 1998, 13, 37-57.

28. Davies, C.; Jenkins, R. She has different fits to me: How people with learning difficulties see themselves. Disabil. Soc. 1997, 12, 95-109.

29. Khan, R.F. Mental Retardation and Paternalistic Control. In Moral Issues in Mental Retardation; Laura, R.S., Ashman, F., Eds.; Croom Helm: London, UK, 1985.

30. Shapiro, R.J.; Rohde, G.L. Falling through the Net: Toward Digital Inclusion; A report on American's access to technology tools; The Secretary of Commerce: Washington, DC, USA, 2000.

31. D'Aubin, A. Working for barrier removal in the ICT area: Creating a more accessible and inclusive Canada. Inf. Soc. 2007, 23, 193-201.

32. Hoppestad, B.S. Current perspective regarding adults with intellectual and developmental disabilities accessing computer technology. Disabil. Rehabil. Assist. Technol. 2013, 8, 190-194.

33. Fox, S. Americans Living with a Disability and Their Technology Profile; PewInternet: Washington, DC, USA, 2011. Available online http://pewinternet.org/ /media//Files/Reports/ 2011/PIP_Disability.pdf (accessed on 6 March 2013).

34. National Telecommunications \& Information Administration and Economic \& Statistical Administration. Exploring the Digital Nation: America's Emerging Online Experience; U.S. Department of Commerce: Washington, DC, USA, 2013. Available online: http://www.ntia.doc.gov/files/ntia/publications/exploring_the_digital_nation_-_americas_emerging online_experience.pdf (accessed on 17 June 2013).

35. Dutton, W.; Helsper, E.J. The Internet in Britain: 2007; Oxford Internet Institute: University of Oxford, UK, 2007.

36. Office for National Statistics. Statistical Bulletin: Internet Access Quarterly Update Q3. Available online: http://www.ons.gov.uk/ons/dcp171778_286665.pdf (accessed on 17 June 2013).

37. Guo, B.; Bricout, J.C.; Huang, J. A common open space or a digital divide? A social model perspective on the online disability community in China. Disabil. Soc. 2005, 20, 49-66.

38. Chadwick, D.; Fullwood, C.; Wesson, C. Intellectual Disability, Identity and the Internet. In Handbook of Research on Technoself: Identity in a Technological Society; Luppicini, R., Ed.; IGI Global: Hershey, PA, USA, 2013; pp. 229-254.

39. McClimens, A.; Gordon, F. People with intellectual disabilities as bloggers: What's social capital got to do with it anyway? J. Intell. Disabil. 2009, 13, 19-30. 
40. Carey, A.C.; Friedman, M.G.; Bryen, D.N.; Taylor, S.J. Use of electronic technologies by people with intellectual disabilities. Mental Retard. 2005, 43, 322-333.

41. Internet World Stats U.S.A. Available online: http://www.internetworldstats.com/ am/us.htm (accessed on 6 March 2013).

42. Gutiérrez, P.; Martorell, A. People with intellectual disability and ICTs. Rev. Comun. 2011, 36, 173-180.

43. Internet World Stats Spain. Available online: http://www.internetworldstats.com/eu/es.htm (accessed on 6 March, 2013).

44. Feng, J.; Lazar, J.; Kumin, L.; Ozok, A. Computer Usage by Young Individuals with Down Syndrome: An Exploratory Study. In Proceedings of Assets '08 Proceedings of the 10th International ACM SIGACCESS Conference on Computers and Accessibility, Nova Scotia, Canada, 13-15 October 2008; pp. 35-42.

45. Palmer, S.B.; Wehmeyer, M.L.; Davies, D.K.; Stock, S.E. Family members' reports of the technology use of family members with intellectual and developmental disabilities. J. Intell. Disabil. Res. 2012, 56, 402-414.

46. Wehmeyer, M.L. National survey of the use of assistive technology by adults with mental retardation. Mental Retard. 1998, 36, 44-51.

47. Wehmeyer, M.L. Assistive technology and students with mental retardation: Utilization and barriers. J. Spec. Educ. Technol. 1999, 14, 48-58.

48. Aspinall, A.; Hegarty, J.R. ICT for adults with learning disabilities: An organisation-wide audit. Br. J. Educ. Technol. 2001, 32, 365-372.

49. Hoppestad, B.S. Inadequacies in computer access using assistive technology devices in profoundly disabled individuals: An overview of the current literature. Disabil. Rehabil. Assist. Technol. 2007, 2, 189-199.

50. Parsons, S.; Daniels, H.; Porter, J.; Robertson, C. The use of ICT by adults with intellectual disabilities in day and residential services. Br. J. Educ. Technol. 2006, 37, 31-44.

51. Kennedy, H.; Evans, S.; Thomas, S. Can the Web be made accessible for people with intellectual disabilities? Inf. Soc. 2010, 27, 29-39.

52. Wehmeyer, M.L.; Smith, S.J.; Palmer, S.B.; Davies, D.K. The effect of student-directed transition planning with a computer-based reading support program on the self-determination of students with disabilities. J. Spec. Educ. Technol. 2004, 19, 7-22.

53. Goggin, G.; Newell, C. Digital Disability: The Social Construction of Disability in New Media; Rowman \& Littlefield: Lanham, MD, USA, 2003.

54. The United Nations. Convention on the Rights of Persons with Disabilities. Available online: $\mathrm{http} / / /$ www.un.org/disabilities/convention/conventionfull.shtml (accessed on 21 June 2013).

55. The Equality Act; HM Treasury Office: London, UK, 2010.

56. Petrie, H.; Hamilton, F.; King, N.; Pavan, P. Remote Usability Evaluations with Disabled People. In Proceedings of CHI '06 Proceedings of the SIGCHI Conference on Human Factors in Computing Systems, Montréal, Québec, Canada, 22-27 April 2006; pp. 1133-1141.

57. eAccessibility of Public Sector Services in the European Union; Cabinet Office, e-Government Unit: London, UK, 2005. 
58. Kennedy, H. Net work: The professionalisation of Web design. Media Culture Soc. 2010, 32, 187-203.

59. Li-Tsang, C.; Yeung, S.; Chan, C.; Hui-Chan, C. Factors affecting people with intellectual disabilities in learning to use computer technology. Int. J. Rehabil. Res. 2005, 28, 127-133.

60. Wong, A.W.; Chan, C.C.; Li-Tsang, C.W.; Lam, C.S. Competence of people with intellectual disabilities on using human-computer interface. Res. Dev. Disabil. 2009, 30, 107-123.

61. Blackburn, C.; Read, J. Using the Internet? The experiences of parents of disabled children. Child. Care Health Dev. 2005, 31, 507-515.

62. Blackburn, C.; Read, J.; Hughes, N. Carers and the digital divide: Factors affecting Internet use among carers in the UK. Health Soc. Care Commun. 2005, 13, 201-210.

63. Parsons, S.; Daniels, H.; Porter, J.; Robertson, C. Resources, staff beliefs and organizational culture: Factors in the use of information and communication technology for adults with intellectual disabilities. J. Appl. Res. Intell. Disabil. 2008, 21, 19-33.

64. Seale, J.K. Strategies for supporting the online publishing activities of adults with learning difficulties. Disabil. Soc. 2007, 22, 173-186.

65. Löfgren-Mårtenson, L. Love in Cyberspace: Swedish young people with intellectual disabilities and the internet. Scand. J. Disabil. Res. 2008, 10, 125-138.

66. Birnie, S.A.; Horvath, P. Psychological predictors of Internet social communication. J. Comput.-Mediat. Commun. 2002, 7. Available online: http://jcmc.indiana.edu/ vol7/issue4/horvath.html (accessed on 9 March 2013).

67. Johnson, R.; Hegarty, J.R. Websites as educational motivators for adults with learning disability. Br. J. Educ. Technol. 2003, 34, 479-486.

68. Dawe, M. Desperately Seeking Simplicity: How Young Adults with Cognitive Disabilities and Their Families Adopt Assistive Technologies. In Proceedings of the CHI Conference, Montreal, QC, Canada, 22-27 April 2006.

69. Bunning, K.; Heath, B.; Minnion, A. Communication and empowerment: A place for rich and multiple media? J. Appl. Res. Intell. Disabil. 2009, 22, 370-379.

70. Maes, B.; Lambrechts, G.; Hostyn, I.; Petry, K. Quality-enhancing interventions for people with profound intellectual and multiple disabilities: A review of the empirical research literature. J. Intell. Dev. Disabil. 2007, 32, 163-178.

71. Cummings, J.N.; Sproul, L.; Kiesler, S.B. Beyond hearing: Where the real-world and online support meet. Group Dyn. Theory Res. Pract. 2002, 6, 78-88.

72. Goodley, D. Locating self-advocacy in models of disability: understanding disability in the support of self-advocates with learning disabilities. Disabil. Soc. 1997, 12, 367-379.

73. Hughes, B.; Patterson, K. The social model of disability and the disappearing body: Towards a sociology of impairment. Disabil. Soc. 1997, 12, 325-340.

74. Bowker, N.; Tuffin, K. Dicing with deception: People with disabilities' strategies for managing safety and identity online. J. Comput.-Mediat. Commun. 2003, 8. Available online: http://onlinelibrary.wiley.com/doi/10.1111/j.1083-6101.2003.tb00209.x/full (accessed on 21 June 2013). 
75. Thoreau, E. Ouch!: An examination of the self-representation of disabled people on the Internet. $J$. Comput.-Mediat. Commun. 2006, 11. Available online: http://onlinelibrary.wiley.com/doi/10.1111/ j.1083-6101.2006.00021.x/full (accessed on 21 June 2013).

76. McVilly, K.R.; Stancliffe, R.J.; Parmenter, T.R.; Burton-Smith, R.M. "I get by with a little help from my friends": Adults with intellectual disability discuss loneliness. J. Appl. Res. Intell. Disabil. 2006, 19, 191-203.

77. Kydland, F.; Molka-Danielson, J.; Balandin, S. Examining the Use of the Social Media tool "Flikr" for Impact on Loneliness for People with Intellectual Disability; Akademika forlag: Trondheim, Norway, 2012. Available online: http://tapironline.no/fil/vis/1036 (accessed on 10 March 2013).

78. Holmes, K.M.; O’Laughlin, N. The experiences of people with learning disabilities on social networking sites. Br. J. Learn. Disabil. 2012. doi:10.1111/bld.12001.

79. Burke, M.; Kraut, R.; Williams, D. Social Use of Computer-Mediated Communication by Adults on the Autism Spectrum. In Proceedings of the 2010 ACM Conference on Computer Supported Cooperative Work, Baltimore, MD, USA, 15-19 February 2010; pp. 425-434.

80. Shpigelman, C.; Reiter, S.; Weiss, P.L. E-Mentoring for youth with special needs: Preliminary results. Cyberpsychol. Behav. 2008, 11, 196-200.

81. Cromby, J.; Standen, P. Cyborgs and Stigma: Technology, Disability, Subjectivity. In Cyberpsychology; Gordo-Lopez, A.J., Parker, I., Eds.; Routledge: New York, NY, USA, 1999; pp. 95-112.

82. Park, B. A method for studying the development of impressions of real people. J. Personal. Soc. Psychol. 1986, 51, 907-917.

83. Dowse, L. Contesting practice, challenging codes: Self advocacy, disability politics and the social model. Disabil. Soc. 2001, 16, 123-141.

84. Reimer-Reiss, M.L.; Whacker, R.R. Factors associated with assistive technology discontinuance among individuals with disabilities. J. Rehabil. 2000, 66, 44-50.

85. Center for Universal Design. The principles of Universal Design. Available online: http://www.ncsu.edu/project/design-projects/udi/center-for-universal-design/the-principles-ofuniversal-design/ (accessed on 4 March 2013).

86. Keskinen, T.; Heimonen, T.; Turunen, M.; Rajaniemi, J.; Kauppinen, S. SymbolChat: A flexible picture-based communication platform for users with intellectual disabilities. Interact. Comput. 2012, 24, 374-386.

87. World Wide Web Consortium (W3C). How people with disabilities use the web Available online: http://www.w3.org/WAI/intro/people-use-web/principles (accessed on 1 May 2013).

88. World Wide Web Consortium (W3C). Web Content Accessibility Guidelines (WCAG) Overview. Available online: http://www.w3.org/WAI/intro/wcag.php\#components (accessed on 1 May 2013).

89. World Wide Web Consortium (W3C). Diversity of web users. Available online: http://www.w3.org/WAI/intro/people-use-web/diversity\#cognitive (accessed on 1 May 2013).

90. Zisimospoulos, D.; Sigafoos, J.; Koutromanos, G. Using video prompting and constant time delay to teach an internet search basic skill to students with intellectual disabilities. Educ. Train. Autism Dev. Disabil. 2011, 46, 238-250. 
91. Williamson, K.; Schauder, D.; Stockfield, L.; Wright, S.; Bow, A. The role of the internet for people with disabilities: Issues of access and equity for public libraries. Aust. Libr. J. $2000,50$. Available online: http://au.vlex.com/vid/role-people-disabilities-issues-equity-52919268 (accessed on 21 June 2013).

92. Li-Tsang, C.W.P.; Chan, C.C.H.; Lam, C.; Hui-Chan, C.; Yeung, S. Evaluations of an information and communication technology (ICT) training programme for persons with intellectual disabilities. Lect. Notes Comput. Sci. 2004, 3118, 1032-1038.

93. Hegarty, J.R. Interchange-Promoting International Friendship-Links for People with Intellectual Impairment. In Improving the Quality of Life for the European Citizen; Placencia-Porrero, I., Ballabio, E., Eds.; IOS Press: Amsterdam, The Netherlands, 1998; pp. 179-184.

94. Kennedy, H. Going the extra mile: Emotional and commercial imperatives in new media work. Convergence 2009, 15, 177-196.

95. Bricout, J.C.; Porterfield, S.L.; Tracey, C.M.; Howard, M.O. Linking models of disability for children with developmental disabilities. J. Soc. Work Disabil. Rehabil. 2004, 3, 45-67.

96. Burchardt, T. Capabilities and disability: The capabilities framework and the social model of disability. Disabil. Soc. 2004, 19, 735-751.

(C) 2013 by the authors; licensee MDPI, Basel, Switzerland. This article is an open access article distributed under the terms and conditions of the Creative Commons Attribution license (http://creativecommons.org/licenses/by/3.0/). 